Article

\title{
Influence of Sample Processing on the Analysis of Carotenoids in Maize
}

\section{Sol Rivera and Ramon Canela *}

Department of Chemistry, Lleida University, Alcalde Rovira Roure, 191, Lleida 25198, Spain

* Author to whom correspondence should be addressed; E-Mail: canela@quimica.udl.cat; Tel.: +34-973-702-843; Fax: +34-973-238-264.

Received: 4 September 2012; in revised form: 13 September 2012 / Accepted: 13 September 2012 / Published: 21 September 2012

\begin{abstract}
We performed a number of tests with the aim to develop an effective extraction method for the analysis of carotenoid content in maize seed. Mixtures of methanol-ethyl acetate $(6: 4, \mathrm{v} / \mathrm{v})$ and methanol-tetrahydrofuran $(1: 1, \mathrm{v} / \mathrm{v})$ were the most effective solvent systems for carotenoid extraction from maize endosperm under the conditions assayed. In addition, we also addressed sample preparation prior to the analysis of carotenoids by liquid chromatography (LC). The LC response of extracted carotenoids and standards in several solvents was evaluated and results were related to the degree of solubility of these pigments. Three key factors were found to be important when selecting a suitable injection solvent: compatibility between the mobile phase and injection solvent, carotenoid polarity and content in the matrix.
\end{abstract}

Keywords: carotenoids; extraction; solubility; injection solvent; liquid chromatography

\section{Introduction}

The choice of extraction methods for carotenoid analysis of food matrices is crucial because errors associated with the extraction process are potentially significant [1]. Given the wide variety of food products containing diverse carotenoids, there is no universally accepted or standard method for carotenoid extraction. The most widely accepted procedures involve extraction with organic solvents, including pentane, hexane, dichloromethane, chloroform, tetrahydrofuran (THF), methanol (MeOH), ethanol (EtOH), acetone, ethyl acetate, $n$-butanol, and petroleum ether [2-6]. Many techniques propose the use of freeze-dried material [7], a saponification step to hydrolyze carotenol esters, and the 
removal of lipids and chlorophylls, which may interfere with the chromatographic detection of carotenoids $[4,5,8]$. MeOH and THF are commonly used as first extraction solvents for maize seeds. Hexane, petroleum ether and ethyl ether are applied as second extraction solvents [9-13]. Although THF and ethyl ether are widely used because of their high capacity to solubilize carotenoids, such solvents can form peroxides, which can rapidly degrade carotenoids and may contribute to secondary products [14]. The addition of antioxidants, such as 2,6-bis(1,1-dimethylethyl)-4-methylphenol (BHT), to the solvent is therefore recommended [5]. In order to minimize auto-oxidation and cis-trans isomerization, carotenoid extraction must be carried out rapidly, avoiding exposure to light, oxygen, high temperatures and pro-oxidant metals, such as iron or copper [5].

Here we propose a new method for extracting carotenoids for maize and improved the performance of a chromatographic system which allows the separation of various carotenoids in less than $15 \mathrm{~min}$. In addition, we provide information about the injection solvent and carotenoid concentrations recommended for this system.

\section{Results and Discussion}

\subsection{Improvements in the Extraction Process}

Initially, the method described by Naqvi [13] was used to extract carotenoids from maize endosperm. However, as this approach involves THF in the first step of the carotenoid extraction procedure (Section 3.3.1), we replaced it to prevent the formation of peroxides, which are known to catalyze carotenoid decomposition. Thus, we evaluated five modifications of the solvent system used to extract total carotenoids from maize seeds. Modification 1 employed EtOH 100\%; modification 2, acetone $100 \%$; modification 3, acetone $100 \%$, but after weighing the sample, it was covered with water (about $400 \mu \mathrm{L}$ ) and the mixture was allowed to stand at room temperature for $1 \mathrm{~h}$ before starting the extraction; modification 4, acetone-EtOH-hexane (1:1:2, v/v); and modification 5, MeOH-ethyl acetate $(6: 4, v / v)$. Table 1 shows the methods used for carotenoid extraction. Each extraction was replicated two or three times and the mean value of the total carotenoid content was used as the Output Factor. Higher values indicate greater extraction efficiency. The total carotenoid content was calculated spectrophotometrically using the following equation [15]:

$$
\mathrm{C}=\frac{\mathrm{Abs} \times 10^{4} \times \mathrm{V}}{\mathrm{A}_{\mathrm{lcm}}^{\mathrm{1} \%} \times \mathrm{W}}
$$

where $\mathrm{A}_{1 \mathrm{~cm}}^{1 \%}=$ absorption coefficient, which is defined as the theoretical absorbance of a solution of $1 \%$ $(\mathrm{w} / \mathrm{v})$ concentration (i.e., $\mathrm{g}$ in $100 \mathrm{~mL}$ ) in a cuvette with a path length of $1 \mathrm{~cm}$. Lutein and zeaxanthin are the major carotenoids in maize. Therefore, an average value for $\mathrm{A}_{1 \mathrm{~cm}}^{1 \%}$ of 2,332 was used [15]. $\mathrm{C}=$ total carotenoid content $(\mu \mathrm{g} / \mathrm{g})$ in a given sample on dry weight basis. Abs $=$ absorbance measured at $450 \mathrm{~nm}$. $\mathrm{V}=$ volume $(\mathrm{mL}) . \mathrm{W}=$ weight of sample $(\mathrm{g}) \cdot 10^{4}=$ conversion factor to obtain the concentration in units of $\mu \mathrm{g} / \mathrm{g}$.

The total carotenoid content obtained with the six methods ranged from 106.5 to $142.1 \mu \mathrm{g} / \mathrm{g} \mathrm{DW}$. The percentage of non-extracted carotenoids was calculated by assigning a value of $100 \%$ to the method that resulted in the highest total carotenoids extracted (Table 1). 
Table 1. Total carotenoids extracted from maize endosperm with the different solvent systems.

\begin{tabular}{cccccc}
\hline $\begin{array}{c}\text { Modified } \\
\text { method }\end{array}$ & Solvents & Ref. & Replicates & $\begin{array}{c}\text { Output Factor }^{\mathbf{c}} \\
(\boldsymbol{\mu g} / \mathbf{g ~ D W})\end{array}$ & $\begin{array}{c}\text { \% Non-extracted } \\
\text { carotenoids }\end{array}$ \\
\hline 1 & EtOH & {$[16,17]$} & 2 & $111.8 \pm 7.10$ & 21.3 \\
2 & $\begin{array}{c}\text { Acetone } \\
\text { Acetone }\end{array}$ & {$[18,19]$} & 3 & $106.5 \pm 2.61$ & 25.0 \\
4 & {$[20]$} & 3 & $126.3 \pm 2.50$ & 11.10 \\
5 & $\begin{array}{c}\text { Acetone-EtOH-hexane } \\
(1: 1: 2, \mathrm{v} / \mathrm{v})\end{array}$ & {$[21]$} & 2 & $120.9 \pm 3.64$ & 14.9 \\
5 & $\begin{array}{c}\mathrm{MeOH}-\mathrm{ethyl-acetate} \\
(6: 4, \mathrm{v} / \mathrm{v})^{\mathrm{b}}\end{array}$ & - & 3 & $141.6 \pm 2.12$ & 0 \\
Reference & $\mathrm{MeOH}-\mathrm{THF}(1: 1, \mathrm{v} / \mathrm{v})$ & {$[13,22,23]$} & 3 & $142.1 \pm 1.94$ & 0 \\
\hline
\end{tabular}

${ }^{\mathrm{a}}$ Samples were hydrated; ${ }^{\mathrm{b}}$ This mixture of solvents was developed in our laboratory; ${ }^{\mathrm{c}}$ Results are presented as means \pm standard deviation (SD) from the same sample batch.

The solvents used to replace THF were selected considering various factors. $\mathrm{MeOH}$ and EtOH were tested because they affect cell wall permeability. This feature is relevant because carotenoids are confined to plant cells and the walls of these cells are complex in terms of chemical composition. We tested mixtures of $\mathrm{MeOH}$, EtOH, acetone (polar solvents), ethyl acetate (medium-polar solvent) and hexane, a non-polar solvent, to search for the co-solubilization of carotenoids with different polarities in the samples. Non-polar carotenoids (e.g., lycopene and $\beta$-carotene) are more soluble in hexane and ethyl acetate [24,25] while more polar carotenoids (e.g., lutein or epoxy carotenoids) show greater solubility in EtOH and acetone [6,26]. Because acetone is widely used for carotenoid extraction [5], we assayed it as the first extraction solvent to replace THF.

The reference method and modification 5 (using THF-MeOH 1:1, v/v and MeOH-ethyl acetate 6:4, $\mathrm{v} / \mathrm{v}$ as solvents, respectively) were the most effective in extracting carotenoids from maize endosperm. The total extracted carotenoids for these two approaches was 142.1 and $141.6 \mu \mathrm{g} / \mathrm{g}_{\mathrm{DW}}$, respectively. Indeed, only with these methods was a complete loss of color observed in the samples (from yellow to white), thereby indicating a suitable extraction capacity. A Student's $t$-test determined that there was no statistically significant difference between the total carotenoid content obtained with the two methods ( $t$ calculated value: $0.27<t$ critical value: 2.78 for 4 degrees of freedom at $\alpha=0.05$ ). Modification 3 resulted in a higher total content of extracted carotenoid than modification 4, followed by modifications 1 and 2 . The total carotenoids extracted with these methods were $126.3,120.9,111.8$ and $106.5 \mu \mathrm{g} / \mathrm{g} \mathrm{DW}$, respectively.

The Student's $t$-test showed a statistically significant difference ( $t$ calculated value: $12.38>t$ critical value: 2.78 for four degrees of freedom at $\alpha=0.05$ ) between the total carotenoid content obtained in modifications 2 and 3. Consequently, it could be concluded that the degree of hydration of the samples accounts for the differences observed in the amount of carotenoids extracted with acetone. Although the presence of water could decrease carotenoid solubility in the extraction solvent, the higher carotenoid content achieved using modification 3 might be attributable to the fact that water enhanced acetone penetration of the endosperm, thus increasing the extractability of the carotenoids [20]. Hence, the degree of sample hydration influences the choice of solvents used to extract carotenoids efficiently and reproducibly [6,27]. 
Howe et al. compared several procedures to extract maize kernels [7]. Among those examined, that described by Kurilich and Juvik [28] was found to be the most reliable method to determine the content of carotenoids in maize. The method requires the saponification of the sample with $80 \%$ potassium hydroxide $\mathrm{w} / \mathrm{v}$ at $85^{\circ} \mathrm{C}$ before extraction of carotenoids with hexane. Although carotenoids in maize are generally not present in the ester form [7], saponification was performed to remove saponifiable lipids, which could interfere with chromatographic analysis. Contrary to Howe et al. [7], our procedures did not require a saponification step since the embryo was removed to eliminate the presence of lipids. These results demonstrate the relevance of initial sample preparation prior to extraction. Modification 5 was chosen to carry out the carotenoid extraction in the further analyses, since the reference method included THF.

\subsubsection{Effect of Adding BHT to the Extraction Solvents}

In order to establish whether the addition of BHT to the extraction solvents used in modification 5 favored carotenoid stability during analysis, transgenic maize TM2 was extracted with and without BHT. Samples were injected into a chromatograph $48 \mathrm{~h}$ after extraction. There was no statistically significant difference between the individual and total carotenoid content in samples in spite of using an anti-oxidant (Table 2). Indeed, the $t$ calculated value was always lower than the $t$ critical value for all cases. These results demonstrate that addition of BHT to the extraction solvents can be omitted provided that carotenoids are analyzed within $48 \mathrm{~h}$ of storage at $-80{ }^{\circ} \mathrm{C}$.

Table 2. Comparison of the individual and total carotenoid content of samples extracted with and without BHT.

\begin{tabular}{cccccc}
\hline Carotenoid & $\begin{array}{c}\text { With BHT } \\
(\boldsymbol{\mu g} / \mathbf{g} \mathbf{D W})\end{array}$ & $\begin{array}{c}\text { Without BHT } \\
(\boldsymbol{\mu g} / \mathbf{g} \mathbf{D W})\end{array}$ & $\boldsymbol{t}$ Calculated & $\boldsymbol{t}$ Critical & $\begin{array}{c}\text { Degree of } \\
\text { freedom }\end{array}$ \\
\hline Astaxanthin & $8.18 \pm 0.06$ & $8.22 \pm 0.06$ & 0.76 & 2.78 & 4 \\
Adonixanthin & $2.46 \pm 0.03$ & $2.51 \pm 0.11$ & 0.80 & 2.78 & 4 \\
Zeax+lut & $2.25 \pm 0.11$ & $2.37 \pm 0.36$ & 0.56 & 2.78 & 4 \\
Adonirubin & $1.52 \pm 0.02$ & $1.52 \pm 0.01$ & 0.36 & 2.78 & 4 \\
Canthaxanthin & $0.98 \pm 0.00$ & $0.96 \pm 0.05$ & 0.47 & 2.78 & 4 \\
Total carotenoids & $15.39 \pm 0.16$ & $15.84 \pm 0.58$ & 1.29 & 2.78 & 4 \\
\hline a $\alpha=0.05 ;$ abbreviations: Zeax+lut, sum of the concentrations of zeaxanthin and lutein; total \\
carotenoids, total carotenoid content.
\end{tabular}

\subsection{Solubility of Carotenoids}

In a previous study [29], we developed a chromatographic system using ultra high performance liquid chromatography (UHPLC), in which 16 carotenoids were separated in less than 15 min. We used this chromatographic system here to separate carotenoids extracted from maize. However, further improvements were made to the system. Hence, the solvent used to dissolve the extracted carotenoids and standards, and the mobile phase were studied. 


\subsubsection{Solubility of the Carotenoids Extracted from Maize in the Injection Solvent}

Most carotenoids are insoluble in water and soluble in organic solvents such as acetone, alcohol, THF, ethyl ether, chloroform and ethyl acetate [27]. Nevertheless, their solubility depends on the presence of different functional groups. To ensure the complete solubilization of these pigments and to avoid incompatibility of the injection solvent with the mobile phase, combinations of acetone and 2-propanol $(i \mathrm{PrOH})$ with the mobile phase (only solvent $\mathrm{A}, \mathrm{ACN}-\mathrm{MeOH} 7: 3, \mathrm{v} / \mathrm{v}$ ) were tested as injection solvent. Acetone and $i \mathrm{PrOH}$ were selected because they are miscible with the mobile phase and less polar than $\mathrm{ACN}$ and $\mathrm{MeOH}$. Therefore, it was considered that these solvents might contribute to increasing the miscibility of carotenes. Solvent A was included as one of the components of the injection solvent since it is advisable to prepare the sample in the operating mobile phase for the best peak shape and sensitivity [30]. Various aliquots of the same maize sample (TM1) were obtained. Each one was dissolved in the same volume of injection solvent. The injection volume was also identical in all cases. This approach facilitated comparison between the corresponding chromatographic peaks and hence evaluation of the effect of the various injection solvents.

Table 3 shows the injection solvents used to dissolve the carotenoids in TM1. No variations in retention time were observed when samples were dissolved in the different injection solvents (data not shown). The highest concentrations of pigments were obtained using a mixture of mobile phase-acetone 6.7:3.3 v/v rather than mobile phase alone as the injection solvent. For example, with this mixture the content obtained for zeaxanthin and lutein was $4.49 \mu \mathrm{g} / \mathrm{g}$ DW while with mobile phase alone this concentration dropped to $3.89 \mu \mathrm{g} / \mathrm{g}$ DW. A reduced percentage of acetone (sample dissolved in mobile phase-acetone 7.5:2.5 v/v) led to a decrease in the content of all carotenoids (Table 3). With this injection solvent, a concentration of $4.20 \mu \mathrm{g} / \mathrm{g}$ DW was obtained for zeaxanthin and lutein. The sample dissolved in ACN-MeOH- $i$ PrOH 8.5:1:0.5 v/v/v did not show any increase in carotenoid contents $(3.05 \mu \mathrm{g} / \mathrm{g}$ DW was obtained for zeaxanthin and lutein). Nevertheless, the lowest content of carotenoids were obtained dissolving the sample in $100 \%$ acetone. Acetone produced $2.20 \mu \mathrm{g} / \mathrm{g} \mathrm{DW}$ of zeaxanthin and lutein content. Therefore, our results indicated that combinations of solvents were more advantageous to improve sample solubility than a single solvent such as acetone.

Table 3. Effect of the injection solvent on the determination of the final carotenoid content of transgenic maize. A homogeneous lyophilized maize sample (TM1) was used for all experiments.

\begin{tabular}{|c|c|c|c|c|}
\hline Injection solvent $^{\mathbf{a}}$ & $\begin{array}{c}\text { Anther } \\
\mu \mathrm{g} / \mathrm{g} D W\end{array}$ & $\begin{array}{c}\text { Adonix } \\
\mu \mathrm{g} / \mathrm{g} D W\end{array}$ & $\begin{array}{c}\text { Lut+zeax } \\
\mu \mathrm{g} / \mathrm{g} \text { DW }\end{array}$ & $\begin{array}{c}\alpha-C r y p t \\
\mu g / g \text { DW }\end{array}$ \\
\hline Acetone $100 \%$ & 0.12 & 1.93 & 2.20 & 0.98 \\
\hline Mobile phase ${ }^{\mathrm{b}}$-acetone $6.7: 3.3, \mathrm{v} / \mathrm{v}$ & 0.24 & 4.71 & 4.49 & 1.36 \\
\hline Mobile phase ${ }^{\mathrm{b}} 100 \%$ & 0.20 & 4.48 & 3.89 & 1.27 \\
\hline Mobile phase ${ }^{\mathrm{b}}$-acetone $7.5: 2.5, \mathrm{v} / \mathrm{v}$ & 0.22 & 4.39 & 4.20 & 1.26 \\
\hline ACN-MeOH- $i \operatorname{PrOH} 8.5: 1: 0.5, \mathrm{v} / \mathrm{v} / \mathrm{v}$ & 0.15 & 3.31 & 3.05 & 1.12 \\
\hline
\end{tabular}


Nevertheless, acetone was required to increase the solubility of the sample under the specific chromatographic conditions used because of the polarity of carotenoids present in TM1 (antheraxanthin, adonixanthin, lutein, zeaxanthin and $\alpha$-cryptoxanthin). Thus, the mixture of mobile phase-acetone 6.7:3.3, v/v was chosen as the injection solvent. Figure 1 shows the separation of a mixture of carotenoids in the transgenic maize line TM2 using the improved UHPLC system.

Figure 1. Carotenoid profile of the transgenic maize line TM2. Abbreviations: Violax, violaxanthin; Astax, astaxanthin; Zeax, zeaxanthin; Lut, lutein; Adonix, adonixanthin; Adonir, adonirubin; cis-Keto, cis-unknown ketocarotenoid; Canthax, canthaxanthin; U-cart, unknown carotenoid; 3-OH-Echinen, 3-OH-echinenone; $\beta$-Cryp, $\beta$-cryptoxanthin; Echin, echinenone; Lyc, lycopene; $\beta$-Zeacarot, $\beta$-zeacarotene, $\beta$-Carot, $\beta$-carotene.

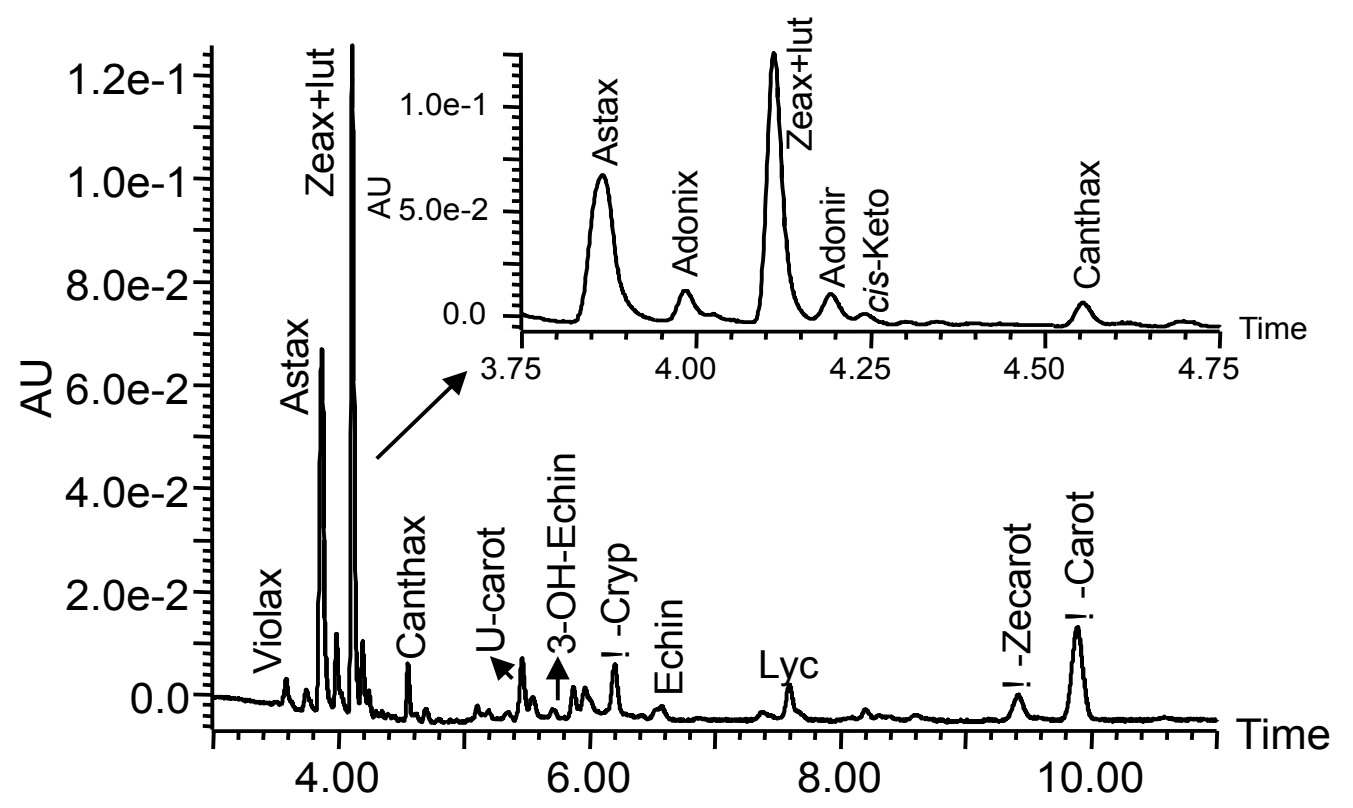

\subsubsection{Preparation of the Carotenoid Standards}

The solvents used to dissolve the carotenoid standards were chosen considering either the previously reported carotenoid solubility or the availability of the absorption coefficient of each pigment.

Stock carotenoid solutions were prepared in EtOH, acetone and hexane [31]. Carotenoid concentrations were determined spectrophotometrically. Table 4 shows the solvent and the value of $\mathrm{A}_{1 \mathrm{~cm}}^{1 \%}$ used to quantify each pigment. Working solutions were prepared from stock solutions by sampling an aliquot and diluting it with injection solvent. Solution concentrations were assessed by UHPLC analysis. For those carotenoids dissolved in hexane (canthaxanthin, $\beta$-cryptoxanthin, $\beta$-carotene, lycopene and phytoene), working solutions were prepared from stock solutions by evaporating an aliquot under nitrogen and diluting it with injection solvent. Calibration curves were obtained from peak area by injecting mixtures of standards. Table 5 shows the linear regression data for each carotenoid standard curve. 
Table 4. Concentrations of carotenoid stock solutions used to build calibration curves.

\begin{tabular}{cccc}
\hline Carotenoid & Solvent & $\mathrm{A}_{1 \mathrm{~cm}}^{1 \%}$ & $\begin{array}{c}\text { Stock carotenoid } \\
\text { concentration }(\boldsymbol{\mu g} / \mathbf{m L})\end{array}$ \\
\hline cis-Neoxanthin & EtOH & 2,380 & $19.64^{\mathrm{a}}$ \\
Violaxanthin & EtOH & 2,550 & $16.26^{\mathrm{a}}$ \\
Antheraxanthin & EtOH & 2,350 & $17.53^{\mathrm{a}}$ \\
Astaxanthin & EtOH & 2,100 & $1.55^{\mathrm{a}}$ and $^{\mathrm{a}} 4.96^{\mathrm{b}}$ \\
Astaxanthin & Injection solvent & - & $5.12^{\mathrm{b}}$ \\
Zeaxanthin & Acetone & 2,340 & $32.31^{\mathrm{a}}$ \\
Lutein & EtOH & 2,550 & $21.57^{\mathrm{a}}$ \\
Canthaxanthin & Hexane & 2,200 & $0.27^{\mathrm{a}}$ and $4.53^{\mathrm{b}}$ \\
Canthaxanthin & Injection solvent & - & $5.70^{\mathrm{b}}$ \\
$\beta$-Cryptoxanthin & Hexane & 2,400 & $35.00^{\mathrm{a}}$ \\
$\beta$-Carotene & Hexane & 2,590 & $24.85^{\mathrm{a}}$ \\
Lycopene & Hexane & 3,450 & $8.26^{\mathrm{a}}$ \\
cis-Phytoene & Hexane & 915 & $16.16^{\mathrm{a}}$ \\
\hline
\end{tabular}

a Concentration was determined spectrophotometrically; ${ }^{\mathrm{b}}$ Concentration was determined by dividing the mass of the carotenoid by the total volume of solution.

Table 5. Linear regression data obtained for several carotenoid standard curves under UHPLC conditions.

\begin{tabular}{|c|c|c|c|c|}
\hline Carotenoid & $\begin{array}{c}\text { Linear range } \\
(\mu \mathrm{g} / \mathrm{mL})\end{array}$ & Slope & Intercept & $\mathbf{R}^{2}$ \\
\hline cis-Neoxanthin & $0.04-19.64$ & $2,481 \pm 7.57$ & $-136.62 \pm 16.28$ & 0.9999 \\
\hline Violaxanthin & $0.03-16.26$ & $2,516 \pm 5.59$ & $-121.93 \pm 12.97$ & 0.9994 \\
\hline Antheraxanthin & $0.03-15.53$ & $2,509 \pm 22.13$ & $-413.83 \pm 4.13$ & 0.9970 \\
\hline Astaxanthin & $0.04-5.12$ & $1,825 \pm 6.43$ & $-50.37 \pm 10.51$ & 0.9999 \\
\hline Astaxanthin ${ }^{a}$ & - & 14,149 & 4414.1 & 0.7741 \\
\hline Lutein & $0.02-17.25$ & $2,475 \pm 81.74$ & $-626.20 \pm 35.78$ & 0.9952 \\
\hline Zeaxanthin & $0.03-17.23$ & $2,578 \pm 38.04$ & $-86.96 \pm 25.8$ & 0.9996 \\
\hline Canthaxanthin & $0.02-5.70$ & $1,787 \pm 4.24$ & $-43.96 \pm 16.13$ & 0.9995 \\
\hline Canthaxanthin ${ }^{b}$ & - & 9,613 & 1583.1 & 0.9320 \\
\hline$\beta$-Cryptoxanthin & $0.04-18.67$ & $2,379 \pm 0.35$ & $-444.17 \pm 31.46$ & 0.9988 \\
\hline Lycopene & $0.3-3.11$ & $1,398 \pm 104.40$ & $-121.72 \pm 24.88$ & 0.9998 \\
\hline$\beta$-Carotene & $0.1-24.85$ & $1,484 \pm 27.22$ & $-189.02 \pm 29.80$ & 0.9998 \\
\hline cis-Phytoene & $0.08-16.16$ & $1,990 \pm 285.46$ & $-259.82 \pm 37.32$ & 0.9989 \\
\hline
\end{tabular}

${ }^{\mathrm{a}}$ Unknown linear range due to the solvent used to prepare the stock solution (EtOH) not being completely soluble; ${ }^{\mathrm{b}}$ Unknown linear range due to the solvent used to prepare the stock solution (hexane) not being completely soluble.

Solubilization problems were encountered for carotenes (when lycopene and $\beta$-carotene were dissolved in hexane) and for ketocarotenoids (when astaxanthin and canthaxanthin were dissolved in EtOH and hexane respectively). Chloroform, dichloromethane, hexane, ethyl acetate and THF $[6,24,32,33]$ are known to dissolve lycopene and $\beta$-carotene. Thus, we chose hexane to solubilize these compounds. Initially, we attempted to prepare $100 \mu \mathrm{g} / \mathrm{mL}$ stock solutions of lycopene and 
$\beta$-carotene in hexane, but a precipitate was observed in the bottom of the vessels. Consequently, to ensure that carotenes were completely dissolved, stock solutions of carotenes were prepared again in hexane but in lower concentrations (Table 4). Thus, stock solutions of $24.85 \mu \mathrm{g} / \mathrm{mL}$ for $\beta$-carotene and $8.26 \mu \mathrm{g} / \mathrm{mL}$ for lycopene were prepared. We did not encounter solubilization problems with these concentrations. In addition, the calibration curves of these pigments (Table 5) indicated that the chromatographic peak areas of carotenes gave a linear plot throughout the concentration range studied.

Similarly, canthaxanthin and astaxanthin were not properly dissolved in hexane and EtOH respectively. Because of the problems of solubilization observed with these compounds, we determined and compared their concentrations using two different methods: dividing the mass of the carotenoid by the total volume of solution (theoretical concentration) and spectrophotometrically (experimental concentration).

The theoretical and experimental concentration obtained for canthaxanthin was 4.53 and $0.27 \mu \mathrm{g} / \mathrm{mL}$, respectively whereas for astaxanthin it was 4.96 and $1.55 \mu \mathrm{g} / \mathrm{mL}$, respectively. The lower concentrations of ketocarotenoids obtained experimentally indicated that hexane and EtOH were not appropriate solvents for canthaxanthin and astaxanthin, respectively. In addition, Table 5 shows that the calibration curves of these two pigments were characterized by a poor $r$-squared $\left(\mathrm{R}^{2}<0.94\right)$. Therefore, we prepared stock ketocarotenoid solutions in the injection solvent of $5.12 \mu \mathrm{g} / \mathrm{mL}$ for astaxanthin and $5.70 \mu \mathrm{g} / \mathrm{mL}$ for canthaxanthin (Table 4). Table 5 shows that the calibration curves of these pigments dissolved in the injection solvent gave a linear plot throughout the concentration range studied. The lack of information about carotenoid absorption coefficients in a variety of organic solvents hampers the use of more appropriate solvents for ketocarotenoids.

We did not encounter any solubilization problems with the concentration range used for: (a) violaxanthin, antheraxanthin, neoxanthin and lutein, dissolved in $\mathrm{EtOH}$; or (b) zeaxathin, dissolved in acetone and (c) $\beta$-cryptoxanthin, dissolved in hexane. As reported previously [26,27,34,35], oxygen-functionalized carotenoids showed satisfactory solubility in $\mathrm{MeOH}, \mathrm{EtOH}$ and acetone.

Given the concentrations of carotenoids expected in maize samples, we did not prepare standard concentrations above $40 \mu \mathrm{g} / \mathrm{mL}$. However, in our experience, higher concentrations of oxygen-functionalized carotenoids can be prepared with the injection solvent used here when needed. For example, concentrations of $100 \mu \mathrm{g} / \mathrm{mL}$ can be prepared for violaxanthin and neoxanthin. If higher carotene concentrations were required, changes in the injection solvent should be made to increase their solubility. For example, when lycopene is the target analyte, the following injection solvents have been used: chloroform $100 \%$, to analyze extracts of tomato fruit pericarps [36]; ethyl acetate 100\% [37] and $n$-butanol-ACN-dichloromethane (3:7:0.1, v/v/v) [38] to analyze extracts of tomato fruit.

Konings et al. [35] prepared stock solutions of lutein, zeaxanthin, $\beta$-carotene and lycopene with the same solvents used in this study. However, they used a mixture of $\mathrm{MeOH}-\mathrm{THF}(7.5: 2.5, \mathrm{v} / \mathrm{v})$ as injection solvent. Under the chromatographic conditions applied, they observed a higher linear range for lutein, zeaxanthin and $\beta$-carotene than for lycopene. The smaller linearity range of lycopene (from 0 to $3.5 \mu \mathrm{g} / \mathrm{mL}$ ) was explained by the lower solubility of this compound in the injection solvent. Nevertheless, the choice of the injection solvent was a compromise between satisfactory solubility of carotenoids, compatibility with the mobile phase, and the absence of peak distortions.

When carotenoid standard solutions are used several times and stored under $\mathrm{N}_{2}$ or Ar, their concentrations should be evaluated since the inert gas introduced various times into the vial evaporates 
the solvent, thereby changing the original carotenoid concentration. Thus, it is advisable to either divide the volume of carotenoid standard solutions into vials, putting only the volume required for each analysis into single vials, or to dry the standard solutions and redissolve these in each analysis. In addition, attention should be paid when many carotenoid standards at high concentrations are solubilized in the same solvent as some might precipitate. Thus, it is preferable to prepare various mixtures of carotenoids to ensure the complete solubilization of all analytes.

\section{Experimental}

\subsection{Chemicals}

$\beta$-Carotene, lycopene, lutein, $\beta$-cryptoxanthin, astaxanthin were purchased from Sigma-Aldrich Fine Chemicals (St. Louis, MO, USA). Canthaxanthin and zeaxanthin were acquired from Fluka (Buchs SG, Switzerland). Phytoene, violaxanthin, neoxanthin, and antheraxanthin were purchased from Carotenature (Lupsingen, Switzerland). $\mathrm{EtOH}, i \mathrm{PrOH}, \mathrm{MeOH}$, ethyl acetate, hexane, ethyl eter, THF, ACN and acetone (HPLC grade purity) were supplied by J.T. Baker (Deventer, The Netherlands). Water was prepared using a Milli-Q reagent water system.

\subsection{Plant Material}

The maize plants were generated by combinatorial nuclear transformation, as reported in Zhu et al. [39]. Transgenic maize lines TM1 and TM2, expressing several carotenogenic genes, were selected to optimize the extraction process and the chromatographic system.

\subsection{Methods}

\subsubsection{Reference Method}

To protect carotenoids from degradation and oxidation, the extraction was conducted under limited light and THF was treated with sodium metal to remove peroxides. The procedure described by Naqvi [13] was used as reference method. Maize endosperm was excised by removing the seed coat and embryo. Only the maize endosperm was used for extraction because carotenoids were designed to accumulate only in this tissue by virtue of the genetic construct used to create the transgenic maize plants (endosperm-specific expression) [39]. Samples were freeze-dried and ground into a fine powder using a mortar and pestle. Maize seeds were lyophilized in order to prevent either microbial or chemical deterioration, which may be caused by the water content in the matrix. In addition, we chose to work with dried rather than fresh material because the former is more amenable to small-scale analysis and more easily homogenized. 50 or 100 [40] mg of sample was extracted with $15 \mathrm{~mL}$ of MeOH-THF $(1: 1, \mathrm{v} / \mathrm{v})$ at $60^{\circ} \mathrm{C}$ for $20 \mathrm{~min}$ and this mixture was continuously shaken. It was then put on ice until it reached room temperature and the liquid phase was filtered into a separatory funnel (if the residue exhibited color after extraction, it was re-extracted with $5 \mathrm{~mL}$ of the first extraction solvent at $60{ }^{\circ} \mathrm{C}$ for $5 \mathrm{~min}$ and the second extract was combined with the first one). $15 \mathrm{~mL}$ of hexane-diethyl ether $(9: 1, \mathrm{v} / \mathrm{v})$ was added to the organic extract and the mixture was shaken vigorously. Then, $20 \mathrm{~mL}$ of saturated sodium chloride solution was added and the mixture was shaken again. The aqueous phase 
was removed and the organic phase was washed with water once again. The organic phase was concentrated under $\mathrm{N}_{2}$ at $37{ }^{\circ} \mathrm{C}$ until the volume was adjusted to $5 \mathrm{~mL} .1 \mathrm{~mL}$ of blank solution was transferred to a cuvette and this was used to set the baseline absorbance of the spectrophotometer at $450 \mathrm{~nm}$. The absorbance of $1 \mathrm{~mL}$ of the organic phase was determined. This organic phase was returned to the tube and left under $\mathrm{N}_{2}$ for further drying. When the sample was completely dry, Ar was flushed into the vial and carotenoids were stored at $-80^{\circ} \mathrm{C}$ until $\mathrm{LC}$ analysis.

No saponification step was included because carotenoids are generally not present in ester forms in maize [7]. This step also has the inherent disadvantage of causing carotenoid losses [12].

When carotenoids are the only pigments present in the samples, extraction is facilitated as the process can be monitored. Consequently, loss of color was used as an indication of complete or satisfactory carotenoid extraction from the matrix.

\subsubsection{Blank Solution}

A blank solution was prepared by carrying out the same extraction process as described in Section 3.3.1, without sample.

\subsubsection{Extraction Using BHT}

BHT at a concentration of $0.1 \%$ was added to the extraction solvents used in modification 5: $\mathrm{MeOH}-$ ethyl acetate 6:4, v/v and hexane-diethyl ether 9:1, v/v. Each extraction was carried out in triplicate.

\subsubsection{Chromatographic Analysis}

UHPLC-PDA analysis was carried out using an ACQUITY Ultra Performance LC $^{\mathrm{TM}}$ system linked to a photodiode array (PDA) 2996 detector (Waters, Milford, MA, USA). MassLynx ${ }^{\mathrm{TM}}$ software version 4.1 (Waters) was used to control the instruments, and for data acquisition and processing. UHPLC chromatographic separation was performed on a reversed-phase column ACQUITY UPLC ${ }^{\circledR}$ BEH $130 \AA \mathrm{C} 18,1.7 \mu \mathrm{m}, 2.1 \times 100 \mathrm{~mm}$ (Waters) and a gradient system with the mobile phase consisting of solvent $\mathrm{A}, \mathrm{ACN}-\mathrm{MeOH}:(7: 3, \mathrm{v} / \mathrm{v})$ and solvent $\mathrm{B}, \mathrm{H}_{2} \mathrm{O} 100 \%$. The gradient program used is shown in Table 6. Column and sample temperatures were set at $32{ }^{\circ} \mathrm{C}$ and $25{ }^{\circ} \mathrm{C}$ respectively. Before use, all solutions were passed through Millex 0.2- $\mu \mathrm{m}$ nylon membrane syringe filters (Millipore, Bedford, MA, USA). The injection volume was $5 \mu \mathrm{L}$.

Table 6. Gradient profile used in the chromatographic separation of carotenoids.

\begin{tabular}{ccccc}
\hline Time (min) & Flow Rate $(\mathbf{m L} / \mathbf{m i n})$ & $\mathbf{A ~ ( \% , ~ v / v ) ~}$ & $\mathbf{B ~ ( \% , v / v )}$ & Curve \\
\hline Initial & 0.4 & 85 & 15 & Linear \\
2.0 & 0.4 & 85 & 15 & Linear \\
3.0 & 0.4 & 100 & 0 & Linear \\
7.0 & 0.4 & 100 & 0 & Linear \\
8.0 & 0.6 & 100 & 0 & Linear \\
11.6 & 0.6 & 100 & 0 & Linear \\
12.6 & 0.4 & 85 & 15 & Linear \\
15.0 & 0.4 & 85 & 15 & Linear \\
\hline
\end{tabular}




\subsection{Ultraviolet and Visible (UV-vis) Spectroscopy}

Absorption spectra and absorbance were recorded using a UNICAM UV/VIS Spectrometer UV2 ATI (Cambridge, UK).

\subsection{Statistical Analysis}

The Student's $t$-test was used to determine differences in the mean values of carotenoid content obtained by the extraction methods. Microsoft Excel version 2010 (Microsoft Corp.) was used for data analysis.

\section{Conclusions}

Several factors, such as the polarity of the carotenoids present in the sample, sample preparation before extraction, and the chemical form of carotenoids in a given sample matrix (free form or bound to other compounds), should be considered in order to develop the most efficient extraction method. The reference method and modification 5 showed the best performance at extracting carotenoids from maize endosperm. As the former involves THF, modification 5 was chosen to carry out carotenoid extraction. This approach circumvents the presence of peroxides in the extraction solvents. The extraction method developed proved to be relatively fast for the determination of carotenoid pigments in maize endosperm. Furthermore, it allowed the simultaneous determination of various carotenoids in the samples. The injection solvent should be chosen on the basis of its compatibility with the mobile phase, and the polarity and concentrations of the carotenoids in the matrix. Thus, we recommend that chromatographic systems be adapted to suit the particular carotenoid profile being analyzed.

\section{Acknowledgments}

We thank P. Christou (PVCF and the Institucio Catalana de Recerca i Estudis Avancats, Barcelona, Spain) for critical comments on the manuscript, and Gerhard Sandmann (Goethe Universitaet, Frankfurt, Germany) for sharing his knowledge of carotenoid analysis. Thanks also go to the Comissionat per a Universitats $i$ Recerca del DIUE de la Generalitat de Catalunya (Barcelona, Spain) and to the European Social Fund (ESF) for the PhD fellowship awarded to Sol M. Rivera. This work was supported by the University of Lleida, Ministry of Science and Innovation (MICINN), Spain (BFU200761413 and CTQ2009-14699-C02-01), and an ERC Advanced Grant (BIOFORCE) to Paul Christou.

\section{References}

1. Kimura, M.; Rodriguez-Amaya, D.B. Sources of errors in the quantitative analysis of food carotenoids by HPLC. Arch. Latinoam. Nutr. 1999, 49 (Suppl. 1), 58S-66S.

2. Meléndez-Martínez, A.J.; Vicario, I.M.; Heredia, F.J. Review: Analysis of carotenoids in orange juice. J. Food Compos. Anal. 2007, 20, 638-649.

3. Oliver, J.; Palou, A. Chromatographic determination of carotenoids in foods. J. Chromatogr. A 2000, 881, 543-555. 
4. Rodriguez-Amaya, D.B.; Kimura, M. Harvestplus Handbook for Carotenoid Analysis, HarvestPlus Technical Monograph Series 2; IFPRI: Washington, DC, USA, and CIAT: Cali, Colombia, 2004.

5. Rodríguez-Bernaldo de Quirós, A.; Costa, H.S. Analysis of carotenoids in vegetable and plasma samples: A review. J. Food Compos. Anal. 2006, 19, 97-111.

6. $\mathrm{Su}$, Q.; Rowley, K.G.; Balazs, N.D.H. Carotenoids: Separation methods applicable to biological samples. J. Chromatogr. B 2002, 781, 393-418.

7. Howe, J.A.; Tanumihardjo, S.A. Evaluation of analytical methods for carotenoid extraction from biofortified maize (Zea mays sp.). J. Agric. Food. Chem. 2006, 54, 7992-7997.

8. Azevedo-Meleiro, C.H.; Rodriguez-Amaya, D.B. Confirmation of the identity of the carotenoids of tropical fruits by HPLC-DAD and HPLC-MS. J. Food Compos. Anal. 2004, 17, 385-396.

9. Berardo, N.; Brenna, O.V.; Amato, A.; Valoti, P.; Pisacane, V.; Motto, M. Carotenoids concentration among maize genotypes measured by near infrared reflectance spectroscopy (NIRS). IFSET 2004, 5, 393-398.

10. Scott, C.E.; Eldridge, A.L. Comparison of carotenoid content in fresh, frozen and canned corn. J. Food Compos. Anal. 2005, 18, 551-559.

11. Menkir, A.; Liu, W.; White, W.S.; Maziya-Dixon, B.; Rocheford, T. Carotenoid diversity in tropical-adapted yellow maize inbred lines. Food Chem. 2008, 109, 521-529.

12. Muzhingi, T.; Yeum, K.J.; Russell, R.M.; Johnson, E.J.; Qin, J.; Tang, G. Determination of carotenoids in Yellow Maize, the effects of saponification and food preparations. Int. J. Vitam Nutr. Res. 2008, 78, 112-120.

13. Naqvi, S. Metabolic Engineering of Complex Pathways in Plants by Combinatorial Genetic Transformation. Doctoral Thesis, University of Lleida, Lleida, Spain, 2009.

14. Most of the methods used to remove peroxides require highly reactive reagents, are time consuming, and call for extreme caution throughout the peroxide elimination process.

15. Mishra, P.; Singh, N. Spectrophotometric and TLC based characterization of kernel carotenoids in short duration maize. Maydica 2010, 55, 95-100.

16. Moros, E.E.; Darnoko, D.; Cheryan, M.; Perkins, E.G.; Jerrell, J. Analysis of xanthophylls in corn by HPLC. J. Agric. Food Chem. 2002, 50, 5787-5790.

17. Howard, L.A.; Wong, A.D.; Perry, A.K.; Klein, B.P. $\beta$-Carotene and ascorbic acid retention in fresh and processed vegetables. J. Food Sci. 1999, 64, 929-936.

18. Matthews, P.D.; Luo, R.; Wurtzel, E.T. Maize phytoene desaturase and $\zeta$-carotene desaturase catalyse a poly- $Z$ desaturation pathway: Implications for genetic engineering of carotenoid content among cereal crops. J. Exp. Bot. 2003, 54, 2215-2230.

19. Rodrigues, P.; Morais, H.; Mota, T.; Olivera, S.; Forgács, E.; Cserháti, T. Use of HPLC and multivariate methods for the evaluation of the stability of colour pigments of paprika (Capsicum annuum) powder. Anal. Chim. Acta 1998, 372, 411-416.

20. Kimura, M.; Kobori, C.N.; Rodriguez-Amaya, D.B.; Nestel, P. Screening and HPLC methods for carotenoids in sweetpotato, cassava and maize for plant breeding trials. Food Chem. 2007, 100, 1734-1746.

21. Sérino, S.; Gomez, L.; Costagliola, G.U.Y.; Gautier, H. HPLC assay of tomato carotenoids: Validation of a rapid microextraction technique. J. Agric. Food Chem. 2009, 57, 8753-8760. 
22. Burkhard, S.; Böhm, V. Development of a new method for the complete extraction of carotenoids from cereals with special reference to durum wheat (Triticum durum Desf.). J. Agric. Food Chem. 2007, 55, 8295-8301.

23. Aluru, M.; Xu, Y.; Guo, R.; Wang, Z.; Li, S.; White, W.; Wang, K.; Rodermel, S. Generation of transgenic maize with enhanced provitamin A content. J. Exp. Bot. 2008, 59, 3551-3562.

24. FAO. Lycopene Extract from Tomate. Available online: http://www.fao.org/fileadmin/templates/ agns/pdf/jecfa/cta/71/lycopene_extract_from_tomato.pdf (accessed on 29 February 2012).

25. Lucini, L.; Pellizzoni, M.; Baffi, C.; Molinari, G.P. Rapid determination of lycopene and $\beta$-carotene in tomato by liquid chromatography/electrospray tandem mass spectrometry. J. Sci. Food Agric. 2012, 92, 1297-1303.

26. Strati, I.F.; Oreopoulou, V. Process optimisation for recovery of carotenoids from tomato waste. Food Chem. 2011, 129, 747-752.

27. Rodriguez-Amaya, D.B. A Guide to Carotenoid Analysis in Foods; International Life Sciences Inst: Washington, DC, USA, 1999.

28. Kurilich, A.C.; Juvik, J.A. Quantification of carotenoid and tocopherol antioxidants in Zea mays. J. Agric. Food Chem. 1999, 47, 1948-1955.

29. Rivera, S.; Vilaró, F.; Canela, R. Determination of carotenoids by liquid chromatography/mass spectrometry: Effect of several dopants. Anal. Bioanal. Chem. 2011, 400, 1339-1346.

30. Waters Corporation. Acquity UPLC BEH Column Care and Use Instructions. Available online: http://www.waters.com/webassets/cms/support/docs/715001371.pdf (accessed on 3 March 2012).

31. Britton, G.; Liaaen-Jensen, S.; Pfander, H. Carotenoids Handbook, 1st ed.; Birkhäuser: Basel, Switzerland, 2004; pp. 3-404.

32. Craft, N.E.; Scares, J.H., Jr. Relative solubility, stability, and absorptivity of lutein and $\beta$-carotene in organic solvents. J. Agric. Food Chem. 1992, 40, 431-434.

33. Shi, J.; le Maguer, M. Lycopene in tomatoes: Chemical and physical properties affected by food processing. Crit. Rev. Biotechnol. 2000, 20, 293-334.

34. Fratianni, A.; Cinquanta, L.; Panfili, G. Degradation of carotenoids in orange juice during microwave heating. LWT-Food Sci. Technol. 2010, 43, 867-871.

35. Konings, E.J.M.; Roomans, H.H.S. Evaluation and validation of an LC method for the analysis of carotenoids in vegetables and fruit. Food Chem. 1997, 59, 599-603.

36. Rosati, C.; Aquilani, R.; Dharmapuri, S.; Pallara, P.; Marusic, C.; Tavazza, R.; Bouvier, F.; Camara, B.; Giuliano, G. Metabolic engineering of beta-carotene and lycopene content in tomato fruit. Plant J. 2000, 24, 413-419.

37. Fraser, P.D.; Enfissi, E.M.A.; Halket, J.M.; Truesdale, M.R.; Yu, D.; Gerrish, C.; Bramley, P.M. Manipulation of phytoene levels in tomato fruit: Effects on isoprenoids, plastids, and intermediary metabolism. Plant Cell 2007, 19, 3194-3211.

38. Lee, M.T.; Chen, B.H. Separation of lycopene and its cis isomers by liquid chromatography. Chromatographia 2001, 54, 613-617.

39. Zhu, C.; Naqvi, S.; Breitenbach, J.; Sandmann, G.; Christou, P.; Capell, T. Combinatorial genetic transformation generates a library of metabolic phenotypes for the carotenoid pathway in maize. Proc. Natl. Acad. Sci. USA 2008, 105, 18232-18237. 
40. The amount depends on the color intensity of the samples. For pale maize samples the extraction of $100 \mathrm{mg}$ of sample is recommended. For darker maize samples the extraction of $50 \mathrm{mg}$ of sample is appropriate.

Sample Availability: Mixture of carotenoids from maiz extracts are available from the authors.

(C) 2012 by the authors; licensee MDPI, Basel, Switzerland. This article is an open access article distributed under the terms and conditions of the Creative Commons Attribution license (http://creativecommons.org/licenses/by/3.0/). 